\title{
Qualitative Community-Based Research and Community-Based Organizations: Are We on the Right Track?
}

\author{
Asha Layne \\ Howard University, Washington D.C., USA
}

\begin{abstract}
This paper examines the role a community-based organization has in locating at-risk adolescents in urban communities. Research has focused attention on violence among Black adolescents because of their exposure of violence in at-risk neighborhoods and the negative impact it has on victims and the community. Though helpful, very little information is known on the impact community-based organizations has on the quality of lives and behaviors of adolescents from at-risk neighborhoods. Policy implications are suggested to increase the rate of community participation in community-based research.
\end{abstract}

Keywords: qulaitative community-based research, community orginaztions, and adolescents

\section{Introduction}

Although a great deal of research has focused on the exposure of violence among at-risk youth, there are few qualitative research studies that examine the impact community organizations have on this population. The active role of community organizations has been central in the well-being of many African American and low-income communities. In recent years, many residents have relied on their communities for social, economic, and medical well-being. This has been more prevalent among communities that have experienced increased rates of poverty and unemployment, disinvestments in local businesses, and discrimination. Neighborhood effects could positively or negatively affect the behaviors and activities seen by its members.

In past studies, researchers have applied Julius Wilson's theoretical analysis of urban neighborhoods to explain the importance and need for community-based organizations. Wilson's analysis described that poverty and race hinder the upward mobility of the disadvantaged class by creating obstacles that limit their access to resources. The value of community-based organizations in urban communities is therefore essential because they serve as a conduit for knowledge.

In studying social interactions and behaviors, the connection between neighborhood effects and social problems cannot be ignored. Studies have explored the impact of neighborhood characteristics, especially neighborhood socioeconomic status, on adolescents' developmental trajectories (E. B. Stewart, E. A. Stewart, \& Simons, 2007, p. 898). Evidence has shown that exposure to violence among adolescents is higher among those residing in urban communities putting them at greater risk. In comparison to their male counterparts, Black females are more likely to become victims of violence, particularly sexual violence, and become infected with a sexually transmitted disease. Social class, neighborhood of residence, education, drug use status, and other social and cultural variables all have significant effects on sexual activity (Fullilove,

Asha Layne, Doctoral Student, Department of Sociology and Anthropology, Howard University. 
Fullilove III, Haynes, \& Gross, 1990, p. 48). These factors have influenced the rate of victimization among Black female adolescents.

This paper examines the role a community-based organization, WAR (Women Accepting Responsibility), has on the physical and mental wellness of its participants under CBPR (the community-based participatory research) paradigm. According to Buchanan, Miller, and Wallerstein (2006), CPBR intervention research is based on two primary assumptions for improving health outcomes and reducing disparities: (1) Interventions can be strengthened if they benefit from community insight and incorporate community theories of etiology and change into the empirical science base; and (2) There is an added value to participate itself for enhancing health. This paradigm was utilized because community development literature has shown that under this paradigm implemented empowerment strategies directly improve health outcomes, cultural sensitivity is acknowledged, and evaluation and assessment tools are inherent in its analysis.

\section{Sexual Violence and Adolescents}

Sexual violence is becoming more common among adolescents as compared to the adult population. In the Unites States, prevalence rates for rape among adolescent girls have ranged from $18 \%$ to $30 \%$ (Coker, McKeown, Sanderson, Davis, Valois, \& Huebner, 2000; Shrier, Pierce, Emans, \& Durant, 1998; Silverman, Raj, Mucci, \& Hathaway, 2001; French \& Neville, 2008, p. 78). In recent literature authors have examined ways to broaden the scope of sexual violence and how it is defined. Traditionally, sexual violence has been classified under the main framework of the Centers for Disease Control and Prevention and other organizations. It has been suggested by French and Neville (2008) that forms of sexual coercion should be included because of the complexity in examining the types of sexual activities that act as precursors to sexual violence. French and Neville (2008) referred to sexual coercion as acts that ranged in a breadth of tactics (e.g., verbal pressure, manipulation, alcohol/drug use, physical or force threat) (p. 78). French and Neville (2008) recognized that Black girls were not part of the sexual violence discourse and are often treated invisibly nationally and within their own communities (p. 78).

Forms of sexual coercion have been a great cause of concern, especially with the increased rates of sexual activity among urban adolescents. African American adolescents, particularly those in low-income urban environments, have been disproportionately impacted by negative sexual health outcomes, such as sexually transmitted infections and HIV (Centers for Disease Control and Prevention, 2002a; 2002b) and unintended pregnancies (Anachebe \& Sutton, 2003). This becomes significant when examining the types of sexual coercion adolescent African Americans encounter. Harper, Gannon, Watson, Catania, and Dolcini (2004) explained that the sexual behaviors between young men and women can be attributed to the learned behaviors and attitudes shared by their peers along with the double-standard viewpoints of sexual fidelity and activity. Their study suggested that peer networks are powerful transmitters of sexual behaviors and attitudes among adolescent African Americans. Their results showed that friendship groups also may serve as great vehicles for the dissemination of information and norms to youth who do not have direct contact with an intervention program, since adolescents talk openly with their friends about sex-related information and have the potential to socially construct more healthy sexual roles and expectations (Harper et al., 2004, p. 360).

\section{Physical Violence and Adolescents}

Physical violence among adolescents is a growing trend in recent years. According to the CDC (Centers for Disease Control) (2012), 9.4\% of students reported that they had been hit, slapped, or physically assaulted 
by a dating partner. Students who are Black (12.2\%) and Hispanic (12.1\%) reported higher rates of dating violence than White students (7.4\%) (Centers for Disease Control and Prevention, 2012). IPV (intimate partner violence) has become an adult and adolescent issue, especially with the increased exposure of violence among teenagers in relationships. In recent years, studies have focused their attention on dating violence among teens, because of its ability to lead to adult victimization and increased risk of contracting a sexually transmitted disease. How adolescents, especially young women, are directly affected by abusive dating (or co-habiting) relationships explains their vulnerability to abuse, the meanings of such experiences, and their subsequent recovery processes (Reynolds \& Sheperd, 2011, p. 315).

Children exposed to dating violence or IPV are exposed to many risks. Studies have shown that exposure to dating violence as an adolescent can be a precursor to IPV victimization in adulthood. An estimated 5.3 million IPV incidents occur each year, resulting in approximately two million injuries and 1,300 deaths (Centers for Disease Control and Prevention, 2003). Sleutal reviewed qualitative studies of adult women that showed marked effects of partner abuse on identity/self-image, as well as loss of agency, perceived future, and trust in relationships (Sleutal, 1998, as cited in Reynolds \& Sheperd, 2011, p. 316). In a study by the CDC, five risk behaviors were found among high school victims who were exposed to dating violence: unhealthy dieting behaviors, attempted suicide, sexual intercourse, episodic heavy drinking, and physical fighting. Data from the 2003 Youth Risk Behavior Survey data indicated that $8.9 \%$ (8.9\% of males and $8.8 \%$ of females) among 14,945 students reported physical dating violence victimization during the 12 months preceding the survey and that students reporting personal dating violence victimization were more likely to engage in four of the five risk behaviors: sexual intercourse, attempted suicide, episodic heavy drinking, and physical fighting (Centers for Disease Control and Prevention, 2006).

\section{STDs (Sexually Transmitted Diseases) and Adolescents}

The rate of STD infection has grown dramatically in recent years among adolescents, especially among racial subgroups. Several reasons have been identified in explaining this occurrence. Studies have shown how sexual and protective practices are influenced by environmental factors, including social context and epidemiological conditions, thus increasing the rate for exposure for more subgroups than others (Upchurch, Mason, Kusunoki, \& Kriechbaum, 2004, p. 276). Extensive literature has shown that micro-level forces (individual behaviors, sex partner selection, and sexual networks) and macro-level forces add to this growing problem. For instance, research focused on micro-level factors has shown that individuals who have non-monogamous sex partners are at increased risk of infection than those with monogamous partners (Adrinopoulos, Kerrigan, \& Ellen, 2006, p. 132). Furthermore, macro-level social and economic forces drive racial differences in sexual network formation in ways that promote and sustain elevated STD rates within Black populations in the United States (Andrinopoulos et al., 2006).

In examining the increased rates of infection in Black communities, the issues of racism, racial segregation, and poverty need to be examined. The marginalization of Blacks in poor communities has created a double jeopardy, which limits their access to resources and social mobility. Resident location and the condition of location also serve as important indicators in measuring sexual activity. Studies mapping the sexual networks of populations at high risk of STDs show that neighborhood and sexual network boundaries are correlated (Potterat, 1992). Therefore, neighborhoods that show physical deterioration are indicative of lower socioeconomic status, which in turn is associated with a breakdown in social relations, with fewer effective 
sanctions and social controls to regulate behavior (Sampson et al., 1997). This has been supported by the prevalence of single-parent households in lower socioeconomic neighborhoods. Sexual and protective practices, in turn, are influenced by environmental factors, including social context and epidemiological conditions (Upchurch et al., 2004, p. 277).

\section{The Current Study}

Data for this current study came from WAR Baltimore City. Table 1 shows that of 2012, Baltimore City has a large population of African Americans at $64 \%$, with the $18 \%$ and under age category comprising the majority of residents at $22 \%$. Table 2 shows the rate of victimization for crime for 2012. Located in northwest, WAR is a nonprofit community-based minority organization that offers a wide array of programs for adults and adolescent women of color within the community. Maintaining direct partnership with schools, WAR is able to disseminate information and positively influence the actions and behaviors of adolescents. By providing supportive, educational, and testing services, WAR has a holistic approach which serves the needs of those in need.

This study adds to the body of existing literature on community-based research by examining the role neighborhoods play into behaviors of adolescents and the effect community-based organizations has on the behaviors of adolescents. The investigation has two hypotheses. Hypothesis 1: It is proposed that community based organizations, unlike formal centered organizations (hospital clinics and police stations) are better institutions to locate and serve at risk populations. This is based on community-based research principles along with literature supporting the use of less formal agents of socialization to influence the behaviors and attitudes of at-risk youth. Hypothesis 2: Adolescent participants directly involved in activities at the community level will be less likely to involve in risky sexual, violent, or unhealthy behaviors.

Table 1

2012 Baltimore City Demographics $(N=621,342)$

\begin{tabular}{lcc}
\hline Variables & Number & Percentage (\%) \\
\hline Race & & \\
Black & $395,173.51$ & 63.6 \\
White & $175,218.44$ & 28.2 \\
Hispanic & $27,339.05$ & 4.4 \\
Other & $31,067.10$ & 5.0 \\
Gender & & \\
Male & $292,652.08$ & 47.1 \\
Female & $328,689.92$ & 52.9 \\
Persons $\leq 5$ & $42,521.26$ & 6.8 \\
Persons $\leq 18$ & $133,588.53$ & 21.5 \\
Persons $\leq 65$ & $73,939.70$ & 11.9 \\
Home ownership & $307,564.29$ & 49.5 \\
Median household income, 2007-2011 & $\$ 40,100$ & N/A \\
\hline
\end{tabular}

Source: U.S. Census Bureau.

Table 2

2012 Crime in Baltimore City

\begin{tabular}{llllll}
\hline Area & Population & Forcible rape & Violent crime & $\begin{array}{l}\text { Aggravated } \\
\text { assault }\end{array}$ & $\begin{array}{l}\text { Murder and non-negligent } \\
\text { manslaughter }\end{array}$ \\
$\begin{array}{l}\text { Baltimore } \\
\text { city }\end{array}$ & 625,474 & 315 & 8,789 & 4,651 & 218 \\
\hline
\end{tabular}

Source: Metropolitan Statistical Area. 


\section{Methodology}

This study is a secondary analysis based on the Growing up Program's longitudinal data of wave 2 taken by OWH (Office of Women's Health). Funded by OWH, the culturally driven gender specific youth program helps to increase self-esteem, healthy behavior, and social skills, and prevent teenage pregnancy, violence, and HIV/STDs for girls between the ages of 12-17. The original study ran from September 2011 to August 2012 during which 71 girls enrolled (four participants below the projected goal). Data were collected from the second wave of participants using OWH national questionnaire developed by GEARS (the Global Equity Analytics and Research Service). OWH is an extension of the United States Department of Health and Human Services that works as one of the leading agencies to promote health and wellness of all U.S. women and girls. Participants were given a 27-page questionnaire before exposure of the program, curriculum, after exposure of the curriculum, and a follow-up during the supplemental period. Participants were pre-tested in September and post-tested in June at the end of the school term.

Questionnaire evaluations were administered by independent local evaluators of Advising Matters L.L.C. Clearance for data collection was obtained from the Office of Management and Budget and was approved by the Institutional Review Board. Each participant was assured confidentiality by receiving an ID number for each completed questionnaire. Data was uploaded and inputted by WAR staff under supervision and was later sent to GEARS.

\section{Curriculum}

This program offers an extensive 36 week long multi-faceted curriculum sessions that provide participants information on sexual health, mental wellness, and violence. Core elements of the curriculum include: self-esteem, anger management, violence prevention, HIV and STI/STD prevention, and activities. Session information was presented on the site of schools to maintain attendance. Supplemental sessions are done beyond the 36 weeks to maintain contact with participants beyond the school term. The curriculum ensures that participants are actively involved by conducting community outreach projects to promote safe healthy practices and awareness.

\section{Recruitment}

Participants of wave 2 were recruited using the non-random sampling procedure of convenient sampling from the contracted schools WAR has direct partnerships with. Participants of wave 2 were recruited from three elementary/middle schools in Baltimore City.

\section{Measures}

\section{Physical Violence}

Assessment for physical violence variable was categorized and measured into three categories: problem-solving, neighborhood conditions, and dating violence. The following questions served as measures for problem-solving: (1) "I take steps to solve the problem instead of complaining about it to everyone else"; (2) "I give into the other person without giving an opinion"; (3) "I tell the other person what I think no matter how they feel"; and (4) "I like to get everything out in the open so that the problem can be solved as quickly as possible”. Response options for questions measuring participant's level of problem-solving was in a five-point Likert scale format.

Assessment for neighborhood conditions variable was measured by the following questions: (1) "There are plenty of safe places to walk or play outdoors in my neighborhood"; (2) "Within walking distance of my house, 
there is a park or playground where I like to walk and enjoy myself, playing sports or games"; (3) "I feel safe when I walk around my neighborhood by myself"; and (4) "There are abandoned and boarded up buildings in my neighborhood". Response options for questions addressing the condition of neighborhoods were in a "True", "False" format.

Assessment for dating violence variable was measured by the following questions: (1) "A person angry enough to hit his or her girlfriend must love her very much"; (2) "Violence between dating partners can improve the relationships"; (3) "Girls sometimes deserve to be hit by boys they date"; (4) "Boys sometimes deserve to be hit by the girls they date"; (5) "A girl angry enough to hit her boyfriend must love him very much"; (6) "There are times when violence between dating partners is okay"; (7) "A boy who makes his girlfriend jealous on purpose deserves to be hit"; (8) "Sometimes violence is the only way to express your feelings"; and (9) "Violence between dating partners is a personal matter and people should not interfere". Response options for dating violence questions were in a five-point Likert scale format.

\section{Sexual Violence}

Assessment for sexual violence variable was based on the following questions: (1) "In the past 30 days have you been forced to have sex by someone who liked you more than as a friend"; (2) "In the past 30 days have you been forced by someone who liked you more than as a friend to do other sexual things that you did not want to do"; (3) "In the past 30 days have you been paid for having sexual relations?"; (4) "In the past 30 days have you been physically hurt or threatened to hurt someone to get them to have sex with you"; and (5) "In the past 30 days had or tried to have sexual relations with someone against their will (other than what you have already mentioned)?" Response options for these questions were in a four-point Likert scale format.

\section{STDs, HIV/AIDS}

Assessment for STD and HIV/AIDS variable was measured under the following two dimensions: knowledge of STDs and AIDS/HIV; and participants' attitudes towards practicing safe sex. Measurements of the latter dimension were: (1) "I will make sure a condom is used when I have sex"; (2) "I will only have one sexual relationship at a time"; (3) "I do not plan on having sex until I am married"; (4) "I would only have sex with a person who I have a long term relationship with"; (5) "I will not have sex with someone who refuses to use a condom"; and (6) "I do not plan on having sex until I am least eighteen years old". Response options for these questions were in a five-point Likert scale format. Questions measuring participants' knowledge of STIs/STDs and HIV/AIDS contained 42 items. Response options included "Yes" and "No" options.

\section{Results}

The first objective of this study is to measure the significance community-based organizations has on the attitudes and behaviors of active participants. It is proposed that community-based organizations, unlike formal centered institutions (e.g., clinics and police stations) are better places to locate and serve at-risk adolescent population. This is based on the principles behind community based research principles along with literature supporting the use of less formal agents of socialization to influence the behaviors and attitudes of at risk youth. Another benefit of using less formal structured institutions for assistance is the lack of potential stigmatization. To ascertain this, the overall participant completion was measured. According to the secondary data, 71 participants were successfully recruited into the Growing up Program, but only 44 participants completed the pre- and post-test national questionnaire. According to the OWH progress report in September 
of 2012, the overall median incomes of households were low with the majority at an average of $\$ 25,000.00$ annual income.

To ascertain whether or not the program curriculum affected the behaviors of participants pre- and post-tests responses were analyzed. Overall, the OWH data focused their attention on participants that were below 15 years and those 15 and older. Ages of participants in the study ranged from 12-20 years old. Data was thus stratified to determine any difference between participants below 15 and those 15 and older. This approach may provide helpful insight into programming needs of younger and older African American adolescents and useful interventions (OWH, 2012).

\section{Sexual Violence}

The results were not known for this measurement because OWH did not measure questions surrounding this variable. Questions concerning sexual coercion or possible rape were not measured as indicated in the OWH annual report summary.

\section{STD, HIV/AIDS}

The results indicate that there was an overall 0.07 points increase in HIV/STI knowledge score between pre- and post-test for all participants (OWH, 2012). Frequencies for HIV knowledge were constructed from the following questions: (1) "You can tell if a person has AIDS by looking at them"; (2) "A person can get AIDS by touching or hugging someone"; (3) "You can get AIDS by having anal sex without a condom"; and (4) "Only people who have sexual intercourse with gay people can get AIDS". Participants that were below 15 had a significantly higher health, HIV knowledge scores than older girls but data on STI knowledge was unknown.

\section{Physical Violence}

The results for this variable were unknown because the national data results did not examine the three categories: problem-solving, neighborhood conditions, and dating violence; as specified earlier in this paper. However, the OWH annual report of wave 2 indicated that older participants (15+) "demonstrated a higher positive attitude towards gangs, higher exposure to gangs, and high levels of delinquent behaviors than younger girls" (OWH, 2012). Examples of delinquent like behaviors were not expressed in the survey.

The problem-solving construct was not measured but anger/conflict management was measured in the annual report using the following questions: (1) "Anger management is a way to learn to control your anger and deal with it in a positive way"; (2) "Keeping your anger inside makes you less angry"; "Conflict cannot be resolved through reaching an agreement between both parties"; (3) "Bullying or shouting angrily at someone is not a form of violence"; and (4) "The symptoms of anger can be physical, emotional, and behavioral". Older and younger participants approximately had equal scores on knowledge of anger/conflict management.

The dating violence construct was not measured but participants' knowledge of domestic violence and attitudes towards relationship was measured. The report showed that there "was no difference between younger and older girls in the proportion of correct answers on domestic violence at the posttest" (OWH, 2012). Knowledge on domestic violence was constructed from the following two questions: (1) "When people abuse their partners they are trying to control them"; and (2) "Dating rape is a criminal offense". Attitudes towards relationship variable were constructed using the following questions: (1) "The most important thing for a woman is to find a man and have children"; (2) "Having sex with a guy means you are having a true relationship"; (3) "If you are still a virgin when you leave school it means you are not desirable"; and (4) "When someone is extremely jealous of a person, it means they love them". The results of this construct was 
not explained beyond question three, in which the annual report only indicated "older girls did significantly better than younger kids" (OWH, 2012). Also, the report indicated that older participants had a higher exposure to relationship violence in the post-test than the pre-test.

In addition, the report indicated that older participants were more likely to abuse drugs than their younger participants. This was measured by participants indicating whether or not they ever used the following: "any drug"; "alcohol"; "tobacco"; "marijuana"; and "cigarettes".

\section{Limitations}

The limitations in this study were detrimental because they did not allow a thorough analysis of the constructed variables. Firstly, the usage of secondary data did not permit any room for questions or better understanding of the collection methods used to ascertain the conclusions made by OWH personnel. Also, by using secondary data it became difficult to obtain data information that was not presented in the OWH annual summary. For example, measurements for the constructed variable, "neighborhood conditions" were not analyzed because the OWH research staff did not focus their attention on these categorical questions in the questionnaire. By only focusing its attention on sexual behaviors, sexual knowledge, and risky behaviors, the OWH annual report does not consider how one's environment or community influences their sexual and non-sexual behavior or knowledge.

Secondly, the methods used to collect data from student participants may have influenced the rate of pre and post-test questionnaire responses and also the validity of the responses. It can be argued that the use of questionnaire to measure one's knowledge or exposure to a curriculum-based program lacks validity because there is no way to determine the truthfulness in the responses. Also, questionnaires have been critiqued by researchers because of their inability to probe responses. This point becomes important to discuss because a 27-page questionnaire was disseminated among adolescent student participants. Research has shown that questionnaires are not suited for all people, especially for older and very young study participants. When taken into consideration, these factors may have contributed to low response rates.

Thirdly, the use of convenient sampling to obtain the 71 participants for wave 2 does not allow one to make generalizations of the findings to the larger population. In this study, OWH's annual report found that younger participants were more knowledgeable about STDs, STIs, and HIV/AIDS than their older counterparts, but because random sampling was not used, one cannot generalize these findings to the larger population.

Finally, the use of a mandatory pre-constructed national government survey limits the involvement or input of community-based organization staff. Some have argued that the involvement of the government may affect the quality and quantity of services being offered. The use of the national survey did not allow any inclusion of WAR staff which may have improved the response rate because the staff members are in direct involvement with participants. From an empirical standpoint, conclusions produced by the questionnaire cannot be adequately drawn from because of limited exposure, unrepresentative observations, and other determinants, such as a cultural element, which may not be taken into account.

\section{Conclusions}

Overall, community-based organizations can be seen as key conduits in transmitting information to hard-to-find populations. WAR has the ability to include at-risk female adolescents into a curriculum-based program that seeks to expose them to healthy behavior practices. The Growing up Program has provided 
assistance to at-risk adolescents in terms of minimizing their exposure to risky behaviors. This paper examined the role one community-based organization has on the physical and mental wellness of its participants under the community-based participatory research paradigm. Attempting to understand how providing supportive, educational, and testing services improves the actions and behaviors of participants is difficult, in that better follow-up measures need to be in place, and that questionnaires could limit one's understanding how and why at-risk adolescents are exposed to risky behaviors. Identifying the active role of community-based organizations in enlightening at-risk adolescent populations is important because those wanting to utilize its participants for research needs must understand participants' communities, and the role they play in encouraging at-risk behaviors.

\section{Policy Recommendations}

CBPR (community-based participatory research) has been proven to be successful because of its integrative process between the community and academics. This success could be jeopardized if members of the community-based organizations are not directly involved in the construction of research design methods that are employed on active participants. According to Quimby (2012), one consideration that should be acknowledged is the knowledge of the community (p. 30). This helps guide the structure and organization for the selected research design that is used. This is essential especially when examining the knowledge of student participants who attend schools located in various neighborhoods. Also, collaboration with community participants is essential for CBPR.

It is recommended that policy makers place equal emphasis on the role one's location of residence and school has in affecting behavior. Policy makers have aggressively examined micro factors like, attitudes in examining behaviors of the at-risk population, but there have been few policies that address the role neighborhoods play in producing at-risk behaviors.

\section{References}

Adrinopoulos, K., Kerrigan, D., \& Ellen, J. M. (2006). Understanding sex partner selection from the perspective of inner-city adolescents. Perspectives on Sexual and Reproductive Health, 38(3),132-138.

Anachebe, N. F., \& Sutton, M . Y. (2003). Racial disparities in reproductive health outcomes. American Journal of Obstetrics and Gynecology, 188(4), S37-S42.

Buchanan, B. R., Miller, F. G., \& Wallerstein, N. B. (2006). Ethical issues in community based participatory research: Balancing rigorous research with community participation (Manuscript submitted for publication).

Fullilove, M. T., Fullilove III, R. E., Haynes, K., \& Gross, S. (1990). Black women and aids prevention: A view towards understanding the gender rules. The Journal of Sex Research, 27(1), 7-64.

French, B. H., \& Neville, H. A. (2008). Black teenage girl's experience with sexual coercion. Black Women, Gender, and Families, 2(2), 77-98.

Centers for Disease Control and Prevention. (2002a). Sexually transmitted disease surveillance. Atlanta, G.A.: U.S. Department of Health and Human Services.

Centers for Disease Control and Prevention. (2002b). U.S. HIV and AIDS cases reported through December 2001 year-end edition. HIV/AIDS Surveillance Report, 13(2), 1-44.

Center for Disease Control and Prevention. (Factsheet). (2006). Retrieved on November 8, 2013 from

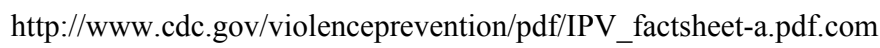

Center for Disease Control and Prevention. (Factsheet). (2012). Retrieved on November 8, 2013 from http://www.cdc.gov/violenceprevention/pdf/IPV_factsheet-a.pdf.com

Coker, A. L., McKeown, R. E., Sanderson, M., Davis, K. E., Valois, R., \& Huebner, E. S. (2000). Severe dating violence and quality of life among South Carolina high school students. American Journal of Preventive Medicine, 19, 220-227. 
Potterat, J. J. (1992). “Socio-geographic space” and sexually transmissible diseases in the 1990's. Today's Life Sciences, 16-22, 31.

Harper, G. W., Gannon, C., Watson, S. E., Catania, J. A., \& Dolcini, M. M. (2004). The role of close friends in African American adolescents' dating and sexual behavior. The Journal of Sex Research, 41(4), 351-362.

Quimby, E. (2012). Doing qualitative community research: Lessons for faculty, students and communities. Bentham Science Publishers: Dubai, U.A.E.

Reynolds, S., \& Shepard, C. (2011). Young women's accounts of intimate partner violence during adolescence and subsequent recovery process: An interpretative phenomenological analysis. Psychology and Psychotherapy, 84(3), 314-334.

Sampson, R. J., \& Morenoff, J. D. (1997). Ecological perspectives on the neighborhood context of urban poverty: Past and present, In J. Brooks-Gunn, G. J. Duncan, \& J. L. Aber (Eds.), Neighborhood poverty: Policy implications in studying neighborhoods (pp. 1-22). New York: Russell Sage.

Shrier, L. A., Pierce, J. D., Emans, J., \& Durant, R. (1998). Gender differences in risk behaviors associated with forced or pressured sex. Archives of Pediatric and Adolescent Medicine, 152, 57-63.

Silverman, J. G., Raj, A., Mucci, L. A., \& Hathaway, J. E. (2001). Dating violence against adolescent girls associated substance use, unhealthy weight control, sexual risk behavior, pregnancy and suicidality. Journal of American Medical Association, 286, 572-579.

Sleutal, M. (1998). Women's experiences of abuse: A review of qualitative research. Issues in Mental Health Nursing, 19(6), 525-539.

Stewart, E. B., Stewart, E. A., \& Simons, R. L. (2007). The effect of neighborhood context on the college aspirations of African American adolescents. American Educational Research Journal, 44(4), 896-919.

Upchurch, D. M., Mason, W. M., Kusunoki, K., \& Kriechbaum, M. J. (2004). Social and behavioral determinants of self-reported std among adolescents. Perspectives on Sexual and Reproductive Health, 36(6), 276-287.

Weinstock, H., Berman, S., \& Cates, Jr., W. (2004). Sexually transmitted diseases among American youth: Incidence and prevalence estimates, 2000. Perspective on Sex Reproductive Health, 36, 6-10. 